\title{
Representações sobre o papel do professor e os conteúdos de ensino no contexto de uma disciplina de licenciatura em Física
}

\section{Representations on the teacher's and teaching content's role in the context of an teacher training Physics subject}

\author{
André Coelho da Silva* \\ Maria José Pereira Monteiro de Almeida**
}

\begin{abstract}
RESUMO
Posicionando-nos em concordância com os chamados modelos críticos de formação docente, objetivamos analisar de que maneira o desenvolvimento de um trabalho pedagógico sobre o funcionamento de aparelhos e exames de diagnóstico médico por imagem atuou junto às representações de licenciandos em Física em face do papel do professor e dos conteúdos de ensino dessa disciplina. Apoiados em noções da Análise de Discurso iniciada por Michel Pêcheux, analisamos informações coletadas por meio de questionários escritos e da gravação das aulas em áudio. No início do trabalho pedagógico desenvolvido, obtivemos indícios de que entre os sentidos que constituíam as representações dos licenciandos acerca de suas futuras profissões e do papel que devem desempenhar como professores estavam sentidos que apontavam para a centralidade dos conteúdos específicos de física. Já ao final do trabalho, obtivemos indícios de que os licenciandos incorporaram e/ou consolidaram em suas representações sentidos que apontam para a relevância do papel social do professor enquanto formador de estudantes para a atuação na sociedade e agente problematizador de sentidos naturalizados, valorizando as relações entre conteúdos de ensino e questões sociais. Nesse sentido, a abordagem de um tema que guarda maior relação com questões sociopolíticas e éticas parece ter facilitado a
\end{abstract}

* Instituto Federal de Educação, Ciência e Tecnologia de São Paulo. Itapetininga, São Paulo, Brasil. E-mail: andco 8@yahoo.com.br.https://orcid.org/0000-0003-1354-4034

** Universidade Estadual de Campinas. Campinas, São Paulo, Brasil. E-mail: mjpma@ unicamp.br. https://orcid.org/0000-0001-7652-4730 
formação de professores em concordância com os chamados modelos críticos de formação docente.

Palavras-chave: Papel do professor. Papel dos conteúdos. Modelos de formação docente. Formação inicial de professores. Representações.

\begin{abstract}
Positioning ourselves in agreement with the so-called critical teacher training models, we aimed to analyze how the development of a pedagogical work on the operation of medical imaging devices and examinations worked in relation to the representations of future Physics teachers, when it comes to on the teacher's and teaching content's roles. Based on notions of Discourse Analysis initiated by Michel Pêcheux, we analyzed information collected through written questionnaires and audio recording of the lessons. At the beginning of this developed pedagogical work, we obtained indications that, among the meanings that constituted the representations of the future teachers about their future professions and the role that they must play as teachers, were meanings that pointed to the centrality of the Physics content. At the end of the study, we obtained indications that the future teachers incorporated and/or consolidated in their representations meanings that point to the relevance of the social role of the teacher as trainer of students for their performance in society and as problematizing agent of naturalized meanings, valuing relations between teaching content and social issues. In this sense, the approach of a theme that has a greater relation with socio-political and ethical issues seems to have facilitated the teachers' training, in agreement with the so-called critical teacher training models.
\end{abstract}

Keywords: Teacher's role. Teaching content role. Teacher training models. Initial teacher training. Representations.

\title{
Introdução
}

Vários autores têm procurado distinguir modelos de formação docente segundo os objetivos que atribuem ao professor e à metodologia proposta para tentar uma formação coerente com esses objetivos. Toti e Pierson (2012), apoiados em Orquiza de Carvalho, distinguiram três bases: a técnica, na qual o professor seria um especialista preparado para aplicar normas; a prática, na qual o professor seria um profissional reflexivo que examina sua prática; e a crítica, na qual o professor assume um viés mais problematizador. De forma 
similar, Abib (2010) aponta a existência de modelos técnicos, modelos práticos e modelos críticos.

Nos modelos técnicos, as questões educacionais poderiam ser resolvidas utilizando técnicas instrumentais. Elas são tratadas como problemas "técnicos". O professor é entendido como um técnico aplicador de conhecimentos produzidos por especialistas e sua formação é compreendida como treinamento. A prática do professor é pouco considerada, uma vez que se trata de apenas aplicar racionalmente a teoria. Esses modelos, ainda com considerável repercussão na realidade educacional, tiveram sua insuficiência amplamente discutida pela literatura da área de formação de professores, sendo considerados academicamente superados. As críticas a eles atribuídas se direcionam às ideias de que bastaria ao professor o domínio do conteúdo que irá ensinar e de que apenas a teoria é primordial, sendo a prática um mero espaço para sua aplicação (ABIB, 2010; AZEVEDO et al., 2012; DINIZ-PEREIRA, 2014).

A complexidade e a imprevisibilidade do trabalho docente acarretaram na valorização dos conhecimentos práticos e das dimensões investigativa e criadora dos professores, dando base aos chamados modelos práticos. A defesa da noção de professor reflexivo, amplamente presente no campo da formação de professores, em linhas gerais, implica em assumir que o professor produz conhecimento refletindo sobre sua própria prática, indo de encontro à vertente que toma o professor como um mero executor de atividades receitadas pelos que se consideram especialistas. Por outro lado, especialmente a partir dos anos 1990, críticas a esse paradigma têm ganhado força. Entre elas as de que seu foco seria a reflexão individual, de que não é atribuída ênfase à função social do professor e de que não se questionam as condições que os professores possuem para refletir, que tipo de reflexão realizam e que elementos agregam a ela. Nesse sentido, a ideia de professor reflexivo continuaria associada a uma base técnica, bastando oferecer treinamentos para que os professores se tornassem reflexivos (ABIB, 2010; ARRUDA; PASSOS; FREGOLENTE, 2012; SLONGO; DELIZOICOV; ROSSET, 2010).

São então enfatizados os modelos críticos de formação, nos quais o foco recai sobre a dimensão político-social do trabalho docente, ampliando o viés da reflexão (ABIB, 2010). Considerando nossas convicções enquanto formadores, posicionamo-nos em concordância com esses modelos, valorizando o papel social do professor como formador de pessoas capazes de se posicionarem e atuarem criticamente na sociedade.

Neste trabalho objetivamos analisar de que maneira o desenvolvimento de um trabalho pedagógico sobre o funcionamento de aparelhos e exames de diagnóstico médico por imagem atuou junto às representações de licenciandos em Física em face do papel do professor e os conteúdos de ensino dessa disciplina. 
Na próxima seção, procuramos caracterizar nossa perspectiva sobre os modelos críticos de formação. Para isso, tomamos como base Carr e Kemmis (1986). Em seguida, apresentamos algumas noções da Análise de Discurso (AD), iniciada por Michel Pêcheux, quanto ao apoio teórico-metodológico para o desenvolvimento do trabalho pedagógico e ao fundamento para a realização das análises das informações coletadas junto aos licenciandos. Na quarta seção, apresentamos as condições de produção do trabalho e comentamos como ocorreu a coleta das informações de pesquisa. Por fim, por meio da mobilização de noções da $\mathrm{AD}$, analisamos essas informações a fim de atingirmos o objetivo proposto.

\section{A formação docente numa perspectiva crítica: alguns apontamentos}

Carr e Kemmis (1986) distinguiram três visões sobre teoria e prática educacional: a das ciências naturais, a interpretativa e a crítica - visões que se aproximam, respectivamente, aos modelos técnicos, práticos e críticos distinguidos por Abib (2010).

Segundo a visão por esses autores considerada das ciências naturais, a teoria educacional revela o que realmente ocorre nas situações educacionais e não o que alguém acha que ocorre. Nesse sentido, a partir da aplicação do método científico, especialistas criariam leis causais para prevê-las e controlá-las, uma vez que sempre haveria soluções objetivas para os problemas enfrentados. Os professores seriam os responsáveis por aplicar os resultados de pesquisa (as leis) de forma eficiente. Essa visão é criticada, entre outras coisas, por considerar que ações e objetos naturais podem ser observados da mesma maneira e por não levar em conta a imensa complexidade de variáveis envolvidas em situações educacionais (CARR; KEMMIS, 1986).

A visão interpretativa pressupõe que as situações educacionais só podem ser interpretadas a partir do ponto de vista dos envolvidos. Logo, ao invés de tentar explicar, prever e controlar as ações dos atores educacionais, busca-se descrever e entender como eles interpretam suas ações e as situações em que agem, as teorias (muitas vezes implícitas) que tomam como base para agir. Os pesquisadores ofereceriam aos sujeitos mecanismos para que aprofundassem suas próprias interpretações, ampliando seu entendimento e o nível de sofisticação da linguagem utilizada para descrever as ações. As práticas seriam influenciadas por meio das reflexões realizadas pelo próprio sujeito - reflexões que proporcionariam mudanças na maneira como as práticas são entendidas. Além de objeções por sua incapacidade de produzir generalizações amplas e 
pela natureza subjetiva dos conhecimentos produzidos, a visão interpretativa é também criticada por não enfatizar que os sentidos atribuídos às situações educacionais pelos sujeitos têm relação direta com elementos históricos e sociais. Eles estruturariam e sustentariam as interpretações individuais, mas também determinariam os tipos de interpretação pertinentes numa dada situação e para um dado grupo. Defende-se, assim, a relevância em investigar os fatores que compõem e sustentam as interpretações individuais. Outras críticas à visão interpretativa são as de que ela: desconsidera explicações que sejam incompatíveis com as interpretações dos próprios sujeitos, ou seja, desconsidera a possibilidade de que essas interpretações sejam distorcidas - tornando-se acrítica ao status quo; sugere mudanças nas formas de interpretar as ações ao invés de mudanças nas ações em si; e mantém o pesquisador em uma posição desinteressada (neutra) em relação às situações educacionais - assim como na visão das ciências naturais -, pois não se preocupa em avaliar criticamente as interpretações dos sujeitos e em alterar de maneira direta suas ações (CARR; KEMMIS, 1986).

De maneira similar à visão interpretativa, a visão crítica considera importante a descrição e o entendimento de como os sujeitos interpretam suas ações e as situações em que agem no âmbito educacional. Entretanto, ela também procura entender de que forma questões históricas e sociais estão envolvidas com essas interpretações, transformando as maneiras pelas quais os sujeitos interpretam e sugerindo maneiras de alterar as condições que dificultam o desenvolvimento de ações com maiores níveis de racionalidade e crítica. Os objetivos de explicação (característica da visão das ciências naturais) e entendimento (característica da visão interpretativa) não são tomados como fins em si mesmos, mas como intermediadores da transformação das práticas educacionais, das estruturas sociais e institucionais e das interpretações dos sujeitos sobre elas. Segundo essa visão, o pesquisador deve participar efetivamente da situação educacional sob investigação, uma vez que sua participação é entendida como uma ação político-social. Passa a haver então uma relação colaborativa entre pesquisadores e participantes da pesquisa: aqueles tornam-se "amigos críticos" que tentam auxiliar estes a superarem os problemas educacionais com que lidam - encaminhando, dessa forma, a superação da dicotomia entre teoria e prática e entre especialistas e aplicadores (CARR; KEMMIS, 1986). Há que se mencionar que Carr e Kemmis (1986) parecem pensar os modelos do ponto de vista da formação continuada de professores, o que, ao nosso ver, não nos impede de pensá-los, ainda que parcialmente, também no âmbito da formação inicial.

Assim, em síntese, podemos afirmar que a visão das ciências naturais, ao designar ao professor o papel de mero aplicador de teorias desenvolvidas por especialistas, supõe que a formação inicial de professores deve ser capaz de lhes transmitir as receitas que devem utilizar com o objetivo de que seus 
futuros alunos adquiram o conhecimento científico. O domínio deste, por sua vez, constituir-se-ia como a finalidade única do ensino.

A visão interpretativa, ao atribuir como principal papel do professor o de refletir sobre suas ações, supõe que, durante a formação inicial, os licenciandos devem ser encorajados a refletir sobre situações que podem ocorrer em sala de aula. Supõe ainda que devem ser proporcionados instrumentos para que possam realizar e aprofundar suas reflexões individuais. Os contextos histórico e social são tratados como planos de fundo e não como algo imbricado com o que ocorre em sala de aula. As relações entre problemas escolares e questões sociais são deixadas de lado. Consequentemente, consideramos que pautar a formação no paradigma interpretativo implica em não valorizar as relações entre conteúdos de ensino e questões sociais.

Já a visão crítica, ao dar ênfase ao papel do professor enquanto transformador de suas práticas educacionais e ressaltar elementos das condições históricas e sociais que estão imbricados com essas práticas, supõe que, durante a formação inicial, seja oportunizado aos licenciandos não apenas a reflexão sobre situações de sala de aula, mas também a reflexão sobre seus condicionantes e sobre possíveis maneiras de torná-las momentos que proporcionem a problematização e a emancipação. Como é dada bastante relevância aos contextos histórico e social imbricados nas relações de ensino e aprendizagem, podemos considerar que pautar a formação no paradigma crítico implica em valorizar as relações entre conteúdos de ensino e questões sociais, fomentando um olhar ampliado para o papel do professor. Este não é visto como o transmissor de conhecimento, nem apenas como o mediador de sua construção pelo aluno, mas como um profissional que, ao mediar a relação entre aluno e conteúdo de ensino, toma o conhecimento como instrumento de questionamento do que se apresenta como natural.

\section{Algumas noções da Análise de Discurso}

Adotamos como apoio teórico-metodológico a $\mathrm{AD}$ na vertente que teve seu início com Michel Pêcheux. Baseamo-nos principalmente em obras de Eni Orlandi, que tem publicações relacionadas à AD no Brasil desde os anos 1970.

Para a $\mathrm{AD}$ a relação da linguagem com a exterioridade é fundamental para a constituição do sentido - exterioridade que é entendida como constitutiva do processo de produção de sentidos e que engloba o contexto imediato em que ocorre a manifestação da linguagem, os interlocutores envolvidos e o contexto 
sociohistórico associado. Tais elementos compõem as chamadas condições de produção do discurso e é a relação entre elas e a linguagem que produz sentidos por meio de mecanismos que a AD visa compreender (ORLANDI, 1987).

Como essa produção é dependente das condições em que ocorre, o discurso deixa de ser entendido como a transmissão de informações do locutor para o(s) receptor(es) e passa a ser visto como efeito de sentido produzido entre os interlocutores, como o espaço em que emergem tais sentidos (ORLANDI, 1992; BRANDÃO, 1999). Embora sua materialidade seja linguística (o texto, a fala, a imagem), o discurso é um objeto teórico, um produto, um objeto construído pela análise - a fala, o texto e a imagem permitem acessar o discurso (ORLANDI, 1992).

Os sujeitos, de acordo com suas posições imaginárias em dada conjuntura sociohistórica, são inscritos em formações ideológicas (ORLANDI, 1987, 2005). Conforme Orlandi (2005, p. 42-43): “As palavras mudam de sentido segundo as posições daqueles que as empregam. Elas 'tiram' seu sentido dessas posições, isto é, em relação às formações ideológicas nas quais essas posições se inscrevem”.

$\mathrm{Na} \mathrm{AD}$ o imaginário é entendido como o mecanismo através do qual o indivíduo se relaciona com o mundo, com a realidade, não sendo algo ficcional (ORLANDI, 2001, p. 18). Como afirma Orlandi (2005, p. 40):

[...] não são os sujeitos físicos nem os seus lugares empíricos como tal, isto é, como estão inscritos na sociedade, e que poderiam ser sociologicamente descritos, que funcionam no discurso, mas suas imagens que resultam de projeções. São essas projeções que permitem passar das situações empíricas - os lugares dos sujeitos - para as posições dos sujeitos no discurso. Esta é a distinção entre lugar e posição.

Por meio do imaginário, portanto, o sujeito se relaciona com a realidade e produz no campo discursivo imagens, isto é, representações dessa realidade.

Por fim, salientamos a coerência entre a $\mathrm{AD}$ e os modelos críticos de formação docente, uma vez que ambos valorizam a influência dos aspectos histórico-sociais junto às interpretações dos sujeitos e defendem o papel do pesquisador como alguém que participa e conhece o contexto da pesquisa e o tema sob investigação. Além disso, a visão crítica procura superar a dicotomia entre teoria e prática e a $\mathrm{AD}$ rejeita a dicotomia entre forma e conteúdo. 


\section{Condições de produção da investigação}

Produzimos uma unidade de ensino sobre aspectos do funcionamento dos aparelhos e exames de radiografia, tomografia computadorizada (CT), tomografia por emissão de pósitrons (PET) e ressonância magnética (RMN). A unidade foi trabalhada com licenciandos em Física de uma instituição pública federal durante onze aulas de uma disciplina obrigatória do curso. Nessa disciplina o primeiro autor deste artigo era o professor. Cada aula teve duração de 150 minutos. Oito licenciandos cursaram a disciplina e sete deles aceitaram colaborar com a pesquisa por meio da assinatura de um termo de consentimento livre e esclarecido.

A coleta de informações para a pesquisa se deu por meio: da gravação das aulas em áudio; da apresentação e entrega de um trabalho em que organizados em duplas os licenciandos realizaram entrevistas com pacientes, médicos e técnicos em radiologia a fim de complementarem as aulas e sanarem dúvidas/ curiosidades sobre os exames de diagnóstico por imagem; de doze questionários escritos: questionário inicial $(\mathrm{QI})$, questionário sobre os exames $(\mathrm{QE})$, questionário final $(\mathrm{QF})$, questionário de avaliação da disciplina (QAD) e questionários ao final de cada aula da unidade de ensino, da segunda até a nona (Q2, Q3, Q4, Q5, Q6, Q7, Q8, Q9 - o número representa a aula da unidade em que o questionário foi aplicado).

$\mathrm{Na}$ seção seguinte, apresentamos análises de informações que nos permitiram compreender como os licenciandos manifestaram diferentes representações após o desenvolvimento do trabalho com a unidade de ensino. Nesse sentido, analisamos trechos de suas falas e respostas que escreveram para questões e itens específicos.

\section{Análise das informações coletadas}

Uma das questões do QI, respondido pelos licenciandos antes da aplicação da unidade de ensino, foi: "Do que você já aprendeu de física neste curso de Licenciatura em Física, o que mais lhe interessou?".

Foram mencionados conteúdos de ensino associados à física: circuitos elétricos, ondulatória, física aplicada aos fenômenos biológicos (mencionada por dois licenciandos), astronomia, gravitação, entre outros; mas também conteúdos 
como o funcionamento básico do cérebro de acordo com a física e as aplicações tecnológicas relacionadas aos tópicos vistos nas disciplinas. Vale notar que não houve respostas com menção a conteúdos associados às disciplinas pedagógicas ou da área de Ensino de Física.

Outra questão do QI foi: "Elabore um texto em que recorda as situações/ experiências mais relevantes de sua vida.".

Entre os pontos destacados pelos licenciandos em suas respostas estão o ingresso e a finalização de cursos, os empregos em que trabalharam, os relacionamentos, as atividades extracurriculares efetuadas, algumas situações vivenciadas dentro da escola e da faculdade, entre outros. Destacamos a seguir uma das respostas obtidas, frisando que os nomes são fictícios e que optamos por manter as grafias originais:

Marina: Como sou da turma do segundo semestre de 2011, hoje posso dizer que o meu amadurecimento cresceu em questão da faculdade de fisica. Hoje posso dizer que cresci e amadureci e aprendi o que é estudar e se sacrificar para ser alguém e querer ser alguém. Mesmo tendo dificuldades e medos, aprendi que enfrentá-los, é a única forma de mostrar a minha força. Não tenho vergonha de dizer que estou a 1 ano a mais na faculdade, pois hoje posso dizer que essa experiência de perder um ano, foi e sempre será a minha melhor escolha, para saber que eu queria ser realmente uma 'física'. (grifo da licencianda).

Interessante notar que Marina se coloca como uma futura física e não como uma futura professora de física. A assunção dessa postura pode ter como uma de suas bases a relevância que costuma ser atribuída pelos licenciandos à disciplina da qual serão docentes e, consequentemente, aos conteúdos específicos a ela associados. Dessa forma, quando questionados a respeito de "o que serão", muitos licenciandos acabam respondendo "serei um físico" e não "serei um professor" ou "serei um professor de física".

Conforme dissemos anteriormente, ao final de cada aula da unidade de ensino aplicamos um questionário. Neles, a primeira questão solicitava para que os licenciandos escrevessem dúvidas e questionamentos sobre a aula, já a segunda questão solicitava que eles explicassem o que tinha sido abordado durante a aula para um amigo. Essas segundas questões foram utilizadas em duas formas: "Escreva uma carta a um amigo(a) explicando-lhe sobre a aula de hoje" e "O que você explicaria a um amigo sobre a aula de hoje".

Analisando as respostas dadas pelo licenciando Augusto às segundas questões dos questionários aplicados aos finais de cada uma das aulas da unida- 
de, notamos que ele sempre descreveu os conteúdos de física que haviam sido tratados sem se preocupar em explicá-los e/ou em descrever também de que maneira eles foram abordados. As respostas apresentadas a seguir foram dadas por Augusto (grifos nossos):

Q2 - A aula de hoje foi sobre exames médicos, de diagnóstico por imagem, onde a fisica teve alta relevância no desenvolvimento. Foram comentados os riscos que estes podem trazer a saúde e como funcionam os equipamentos que realizam estes exames.

Q3 - Na aula de hoje vimos sobre ondas eletromagnéticas, como surgiu as ideias para explicar a luz até chegarmos ao conceito que temos hoje da dualidade da luz.

Q5 - A aula de hoje foi sobre exames médicos, radiografia e CTs, sobre como funcionam, seus beneficios e riscos envolvidos; sobre como foi feita as descobertas dos raios $X$ e sobre a radiação.

Q7 - Na aula de hoje foi feita uma revisão sobre como funciona os exames de radiografia, CT, PET e PET-CT, foi explicado também como é e como funciona o exame de ressonância magnética, onde acabamos discutindo um pouco sobre magnetismo e um pouco de eletromagnetismo para poder entender melhor como funciona o exame de RMN.

Q8 - A aula de hoje foi sobre acidentes radioativos, vimos como funciona as usinas onde aconteceram os acidentes para poder entendê-los, vimos também um vídeo sobre os lugares mais radioativos da Terra.

Logo, entre os sentidos que constituíam as representações dos licenciandos acerca de suas futuras profissões e do papel que devem desempenhar como professores estavam sentidos que apontavam para a centralidade dos conteúdos específicos de física.

Passamos a apresentar agora indícios que sugerem que o trabalho pedagógico com a unidade de ensino contribuiu para que os licenciandos incorporassem e/ ou consolidassem em suas representações sentidos que apontam para a relevância 
do papel social do professor enquanto formador dos estudantes para a atuação na sociedade e agente problematizador de sentidos naturalizados, valorizando as relações entre conteúdos de ensino e questões sociais.

No trabalho que entregaram referente à realização de entrevistas com pacientes e profissionais da área da saúde, duas duplas se manifestaram da seguinte maneira (grifos nossos):

Dupla 1: Dificilmente se vê controle do paciente sobre quantos exames destes foram realizados no ano pela falta de conhecimento sobre o assunto, e também o médico ou o técnico em radiologia não pergunta isso ao paciente.

Dupla 2: [...] Já os exames de Tomografia e Ressonância Magnética, em especial, têm um custo muito elevado devido ao preço da máquina e manutenção da mesma, além do grande número de pessoas envolvidas. Mas, em alguns casos, não há outra solução quando se trata de maiores detalhes e aperfeiçoamento nas imagens. Apesar disso, constatou-se, com o depoimento da [paciente], que algumas pessoas não conseguem realizar o exame que segundo o tecnólogo é simples e tranquilo. Compreende através das entrevistas que jovens estão apresentando hérnia de disco com incidência. Isso se deve, segundo [o tecnólogo], a má postura frente a aparelhos eletrônicos como computadores e principalmente tablets e celular. Percebe-se ainda que além da evolução da medicina, fazendo uso de descobertas científicas, busca maneiras de diagnosticar e resolver problemas que cada vez mais criamos com hábitos e costumes da vida que chamamos de 'moderna'. Tudo isso por não nos cuidarmos e mantermos um ritmo de vida sem qualidade, na grande maioria dos casos.

A preocupação dos licenciandos da primeira dupla com a falta de conhecimento dos pacientes sobre o assunto parece trazer consigo implicitamente a defesa de que ele seja tratado na escola. Afinal, o acesso ao conhecimento que faltaria aos pacientes poderia ser proporcionado de que outras maneiras? Através de conversas com familiares ou médicos? Através dos meios de comunicação? Apesar de essas possibilidades existirem, acreditamos que é algo pouco provável. Já a segunda dupla notou a contradição entre as representações da paciente e do tecnólogo entrevistado a respeito do possível desconforto quando da realização de RMN's, assumindo também uma postura crítica quanto ao que chamam de "vida moderna". 
Durante a apresentação do trabalho para a turma, a licencianda Camila, que atuava como professora de física num curso técnico da área da saúde, disse que passou a tentar conscientizar seus alunos a como falar para os pacientes sobre o funcionamento dos exames de imagem e os riscos envolvidos, conforme sua fala a seguir (lembrando que as aulas foram gravadas):

Camila: [...] Aí você pergunta: cara, você tá explicando esse negócio pra cliente... aí você fala que tem energia suficiente pra causar câncer. Fudeu. O cara não vai querer fazer o exame. Então... antes, na primeira vez que eu dei aula pro curso de radiologia eu não pensei nisso. Agora eu comecei a pensar melhor. Conscientizar eles a como explicar o que que é o exame, a como pensar em falar pro paciente o que que é o exame, quais são os riscos né [...].

Ainda que Camila esteja se referindo a alunos de um curso técnico, ela passou a se preocupar com suas formações para que atuem de uma forma melhor em suas funções sociais.

Uma das questões do QF, aplicado ao final da disciplina, simulava um diálogo fictício entre três personagens: Ivone, professora de física do ensino médio na escola J. Wolff; José, coordenador pedagógico da escola; e L, um licenciando em Física no último semestre do curso e que fazia estágio na escola. Nas lacunas indicadas com "L" os licenciandos deviam dar sequência aos diálogos, complementando e/ou concordando e/ou discordando dos personagens.

Segue um dos trechos do diálogo com a complementação de Jonatan (grifo nosso):

José: Especificamente sobre os raios X e a radioatividade, de que forma você pretende tratá-los com os alunos Ivone?

Ivone: Ish... ainda não pensei muito sobre isso José. O que você acha de discutir sobre as usinas nucleares $L$ ? Ou você tem também outras sugestões?

Jonatan: Exames de imagens são bem aceitos. Os alunos, acredito eu, mostrarão curiosidade. Envolve as famílias sobre os exames feitos. 
Jonatan defendeu a abordagem dos exames de imagem na física do ensino médio porque "envolve as famílias". Nesse sentido, Jonatan, que já atuava como professor, parece acreditar na importância de que os tópicos trabalhados em sala de aula possam ter relação com o ambiente extraescolar vivenciado pelos alunos, afinal, é provável que suas mães, pais, irmãos etc. tenham realizado exames de imagem durante a vida. Sua resposta parece trazer implicitamente a ideia de que é importante tentar informar os estudantes e suas famílias sobre o assunto.

Já em um trecho do diálogo fictício que se referia ao alto custo dos exames médicos mais modernos, Fernando complementou da seguinte maneira (grifo nosso):

Ivone: Acho que é isso mesmo L. Só não entendo por que esses exames, principalmente os mais modernos, são tão caros.

Fernando: É óbvio que existe um jogo de interesses econômicos por de trás e uma jogada, mas há também um grande investimento, pois são muito caros e deve-se ter uma constante manutenção.

Fernando foi capaz de problematizar o sentido naturalizado de que a única causa para o alto valor dos exames de imagem é o fato dos processos de construção, funcionamento e manutenção dos aparelhos possuírem custos elevados.

O último espaço do diálogo a ser completado se relacionava à possibilidade de abordar o funcionamento dos exames de imagem e seus riscos na física do ensino médio (a professora fictícia Ivone afirmava no diálogo que não cabia trabalhá-los nas aulas de física, especialmente pela escassez de tempo). Clara completou da seguinte maneira (grifo nosso):

José: Hum... Interessante esse assunto. Acho que seria legal você falar um pouco sobre isso com seus alunos Ivone...

Ivone: Será José? Acho que essa questão dos riscos e também de coisas relacionadas ao funcionamento desses aparelhos médicos não é importante para os alunos e não cabe dentro das aulas de física. Meu tempo é curto e vou precisar passar muitos exercícios sobre decaimentos radioativos e meia-vida para que eles entendam... 
Clara: É importante sim, além de caber dentro das aulas de física, a população deve se conscientizar sobre esse assunto. Muitas pessoas se submetem a exames de imagem frequentemente e não sabe do risco que corre. Os hospitais não fiscalizam a taxa de radiação que cada pessoa toma por ano.

Clara justificou a necessidade em abordar o assunto no ensino médio porque "a população precisa se conscientizar sobre o assunto".

A segunda questão do QAD era: "Comente pontos positivos e negativos da unidade de ensino sobre exames de diagnóstico médico por imagem (radiografia, tomografia computadorizada, tomografia por emissão de pósitrons e ressonância magnética).”.

Um dos seis licenciandos que responderam parece não ter interpretado o enunciado da questão da maneira como gostaríamos, uma vez que sua resposta aponta pontos positivos e negativos da utilização dos exames de imagem em si:

Camila: Positivo - o avanço das tecnologias sempre é uma ajuda a mais, porém a capitalização gera o uso indiscriminado dos exames pode gerar problemas graves. Mas por conta do mau uso, pois os protocolos de segurança são bem elaborados.

De qualquer forma, adjetivar o substantivo "uso" com a palavra "indiscriminado" sugere um exercício de problematização da licencianda com relação à frequência de realização dos exames. Problematização que também efetua ao apontar a capitalização como a causa do uso indiscriminado, questionando os sentidos naturalizados de que realizar exames de imagem é algo positivo em si e de que o aumento do número de solicitações para que os pacientes realizem exames é algo neutro em termos de interesses em jogo.

Nas respostas dadas pela licencianda Clara a questões do QF também notamos indícios da assunção de uma postura crítica em relação a sentidos socialmente naturalizados: "[...] Se você não faz exames frequentemente, apenas quando realmente é necessário [...]"; e "[...] Muitas pessoas se submetem a exames de imagem frequentemente e não sabe do risco que corre. Os hospitais não fiscalizam a taxa de radiação que cada pessoa toma por ano."

Ao utilizar o advérbio "realmente", Clara parece adotar uma postura de questionamento acerca da necessidade de se realizar exames de imagem sempre que solicitado pelos médicos (sentido socialmente naturalizado). Ou 
seja: nem sempre seria realmente necessário. De forma similar, o complemento necessário ao trecho em que a licencianda demonstra preocupação por muitas pessoas não saberem do risco envolvido na realização de exames de imagem é a defesa de que elas sejam informadas - tarefa que poderia ser desempenhada pela escola, proporcionando a formação dos sujeitos para a atuação na sociedade. Ao afirmar que não há fiscalização sobre a dose de radiação ionizante recebida em procedimentos médicos, Clara se posiciona de maneira bastante crítica, questionando instituições e os papéis sociais que desempenham e/ou deveriam desempenhar.

Notamos indícios nessa mesma direção em respostas de Augusto (grifos nossos):

QF - [...] em todos [os exames] há riscos envolvidos exceto na ressonância eletromagnética, que fosse fazer caso necessário mesmo, que não há problema fazer uma vez pois a probabilidade de algo acontecer por conta da radiação ionizante, mas quanto mais vezes fazer algum maior a probabilidade dessa radiação o afetar.

QF - [Referindo-se aos exames de imagem] "[...] pode-se sim fazê-los, mas se realmente for necessário, pois quanto mais fazê-los mais chance de algo acontecer.

QF - [Sobre inserir tópicos de FMC no ensino médio] 'Sim. Incluiria até porque está no currículo escolar para ser passado para os alunos, mas não só por isso incluiria porque é uma disciplina que envolve uma ciência do cotidiano, digo ciência do cotidiano pois, a tecnologia, equipamentos e a parte social estão completamente envolvidas. [...].

QF - [Sobre inserir tópicos de FMC no ensino médio] [...] É importante para os alunos para conhecerem os fenômenos físicos envolvidos nas vidas cotidianos [...].

QF - [Sobre abordar aspectos do funcionamento dos exames de imagem e os riscos envolvidos no ensino médio] [...] é importante você abordá-lo sim pois é algo que faz parte da vida deles, é a ciência aplicada a vida, do meu ponto de vista é importante. 
QAD - [Sobre a unidade de ensino] Pontos positivos: gostei de usar os exames de diagnósticos por imagem pois faz parte da vida das pessoas atualmente. [...].

Nos dois primeiros trechos, Augusto se utilizou da palavra "mesmo" na frase "fazer caso necessário mesmo"; e da expressão "se realmente" na frase "se realmente for necessário". Ao redigir tais palavras, o licenciando assumiu uma posição problematizadora do sentido naturalizado de que sempre os exames de imagem são necessários, bastando haver a solicitação do médico. Nos outros trechos apresentados, Augusto defendeu a inserção de tópicos de Física Moderna e Contemporânea (FMC) no ensino médio não apenas porque ela é recomendada em documentos oficiais, mas, sobretudo, porque na visão do licenciando trata-se de temas diretamente relacionados a nossas vidas, o que tornaria suas abordagens relevantes no ensino básico. Para Augusto, o mesmo argumento se aplica no que concerne à ideia de abordar aspectos associados aos exames de imagem no ensino médio.

\section{Considerações finais}

Notamos indícios de que os licenciandos incorporaram/consolidaram em suas representações sentidos que apontam para a relevância do professor de física em termos de sua função social, entendendo os conteúdos específicos da disciplina não como fins em si mesmos, mas desempenhando o papel de mediadores junto à atuação dos estudantes na sociedade. Acreditamos que isso ocorreu devido à abordagem de um tema que guarda maior relação com questões sociopolíticas e éticas, como a não explicitação ao paciente dos riscos envolvidos na realização desses procedimentos e o acesso aos exames mais modernos apenas às parcelas economicamente mais favorecidas da sociedade. Nesse sentido, defendemos que o trabalho com temas dessa natureza pode facilitar a formação de professores em concordância com os chamados modelos críticos de formação docente.

A reprodução pelo professor em atuação da forma/conteúdo de ensino pela qual ele foi formado, seja no ensino básico ou no superior, assim como a incorporação de características atribuídas a professores que marcaram sua trajetória de estudante ocorrem em boa medida e são efeitos conhecidos pela literatura (QUADROS et al., 2005; BORGES, 2006). Além de trabalhar com as representa- 
ções já constituídas, parece ser necessário que os formadores adotem, nos cursos de licenciatura, experiências e atitudes que vão de encontro a ideias atreladas ao chamado ensino tradicional, tais como as de que o professor é o transmissor e os alunos os receptores de saberes; a aprendizagem ocorre por simples memorização e repetição; os conteúdos de ensino só fazem sentido no interior da escola, não possuindo qualquer relação com a sociedade ou a cultura geral. Nesse sentido, enquanto formadores, se esperamos que a prática dos futuros professores não seja pautada em muitas das ideias atreladas ao ensino tradicional, não seria conveniente pautarmos nelas nossa prática. Experiências e atitudes que poderíamos chamar de alternativas a essas ideias, além de possuírem potencial para reformular representações formadas durante a educação básica e a própria licenciatura, constituem-se como outras representações possíveis, como outras fontes de inspiração para o futuro professor (FREITAS; VILLANI, 2002; ZIMMERMANN; BERTANI, 2003). Ou seja, acreditamos que dizer/discutir maneiras diferentes de atuar não é suficiente. É necessário que essas maneiras sejam vivenciadas. Nas palavras de Delizoicov (2004, p. 153): "o professor formador desempenha papel exemplar para a atuação docente, tanto ao adotar práticas consistentes com os resultados de pesquisa como ao manter práticas tradicionais de ensino".

Há que se considerar ainda que apresentar aos licenciandos possíveis maneiras de atuar sem colocá-las em prática pode acabar caindo na armadilha das prescrições, ou seja, na tentativa de dizer-lhes autoritariamente o quê, quando e como devem trabalhar (ALMEIDA, 2006).

\section{REFERÊNCIAS}

ABIB, M. L. V. S. A pesquisa em ensino de Física e a sala de aula: articulações necessárias na formação de professores. In: GARCIA, N. M. D. et al. (Orgs.) A pesquisa em ensino de Física e a sala de aula: articulações necessárias. São Paulo: Editora da Sociedade Brasileira de Física, 2010. p. 227-238.

ALMEIDA, M. J. P. M. Prescrições e recomendações ao professor na solução de problemas do ensino na educação em ciências. Ciência \& Ensino, v. 1, n. 1, 2006.

ARRUDA, S. M.; PASSOS, M. M.; FREGOLENTE, A. Focos da aprendizagem docente. Alexandria: Revista de Educação em Ciência e Tecnologia, v. 5, n. 3, 2012.

AZEVEDO, R. O. M.; GHEDIN, E.; SILVA-FORSBERG, M. C.; GONZAGA, A. M. Formação inicial de professores da educação básica no Brasil: trajetória e perspectivas. Revista Diálogo Educacional, v. 12, n. 37, p. 997-1026, 2012. 
BORGES, O. Formação inicial de professores de Física: Formar mais! Formar melhor! Revista Brasileira de Ensino de Física, v. 28, n. 2, p. 135-142, 2006.

BRANDÃO, H. H. N. Introdução à Análise do discurso. Campinas: Editora da Unicamp, 1999.

CARR, W.; KEMMIS, S. Becoming critical: education, knowledge and action research. Deakin University Press, 1986.

DELIZOICOV, D. Pesquisa em ensino de ciências como ciências humanas aplicadas. Caderno Brasileiro de Ensino de Física, v. 21, n. 2, 2004.

DINIZ-PEREIRA, J. E. Da racionalidade técnica à racionalidade crítica: formação docente e transformação social. Perspectivas em Diálogo: Revista de Educação e Sociedade, v. 1, n. 1, p. 34-42, 2014.

FREITAS, D.; VILLANI, A. Formação de professores de ciências: um desafio sem limites. Investigações em Ensino de Ciências, v. 7, n. 3, p. 215-230, 2002.

ORLANDI, E. P. A linguagem e seu funcionamento: as formas do discurso. São Paulo: Pontes, 1987.

ORLANDI, E. P. Análise de discurso: princípios \& procedimentos. Campinas: Pontes, 2005.

ORLANDI, E. P. Apresentação: Cidade Atravessada. In: ORLANDI, E. P. (Org.). Cidade atravessada: os sentidos públicos no espaço urbano. Campinas: Pontes, 2001.

ORLANDI, E. P. O que é linguística. 5. ed. São Paulo: Brasiliense, 1992.

QUADROS, A. L.; CARVALHO, E.; COELHO, F. S.; SALVIANO, L.; GOMES, M. F. P. A.; MENDONÇA, P. C.; BARBOSA, R. K. Os professores que tivemos e a formação da nossa identidade como docentes: um encontro com nossa memória. Ensaio: Pesquisa em Educação em Ciências, v. 7, n. 1, 2005.

SLONGO, I. I. P.; DELIZOICOV, N. C.; ROSSET, J. M. A formação de professores enunciada pela pesquisa na área de educação em Ciências. Alexandria: Revista de Educação em Ciência e Tecnologia, v. 3, n. 3, 2010.

TOTI, F. A.; PIERSON, A. H. C. Compreensões sobre o processo de formação para a docência: concepções de bacharéis e licenciandos sobre a licenciatura em física. Caderno Brasileiro de Ensino de Física, v. 29, n. 3, p. 1074-1107, 2012.

ZIMMERMANN, E.; BERTANI, J. A. Um novo olhar sobre os cursos de formação de professores. Caderno Brasileiro de Ensino de Física, v. 20, n. 1, p. 43-62, 2003.

Texto recebido em 25 de julho de 2017 Texto aprovado em 21 de dezembro de 2017. 